\title{
Controls on preferential recharge to Chalk aquifers
}

\author{
A. M. Ireson * A. P. Butler \\ Department of Civil and Environmental Engineering, Imperial College London, UK
}

\begin{abstract}
There is evidence that, under certain conditions, rapid preferential recharge via the fracture network can occur in Chalk aquifers. This has potentially important implications for contaminant migration through the Chalk unsaturated zone, CUZ, and for groundwater flooding in Chalk catchments. In the case of groundwater flooding, deficiencies in modelling aquifer response have been attributed to inadequate representation of flow processes in the CUZ (Habets et al., 2010). In this paper we consider two complementary approaches for assessing controls on preferential recharge to Chalk aquifers: an empirical approach and a physically-based modelling approach. We show that the main controls on preferential recharge to Chalk aquifers are the characteristics of rainfall events, in terms of duration and intensity, the physical properties of the near-surface, and the antecedent soil moisture in the near surface. We demonstrate a number of deficiencies when past models of the CUZ are applied to the problem of simulating preferential recharge, notably that the assumption of instantaneous equilibrium between fractures and matrix is not valid, particularly during extreme recharge events. In order to simulate preferential recharge, fractures and matrix must be modelled as separate but interacting domains. This was achieved using a dual continua model. The model was computationally demanding, but was able to reproduce observed behaviour, including apparently hysteretic soil moisture characteristic relationships in the near surface, and rapid preferential recharge fluxes in response to high intensity rainfall
\end{abstract}


events.

Key words: Chalk; Groundwater recharge; Richards equation; Unsaturated zone;

Preferential flow; Fractured porous material

* Corresponding author. E-mail address: andrew.ireson@imperial.ac.uk. Telephone: +44 (0)2075946120 


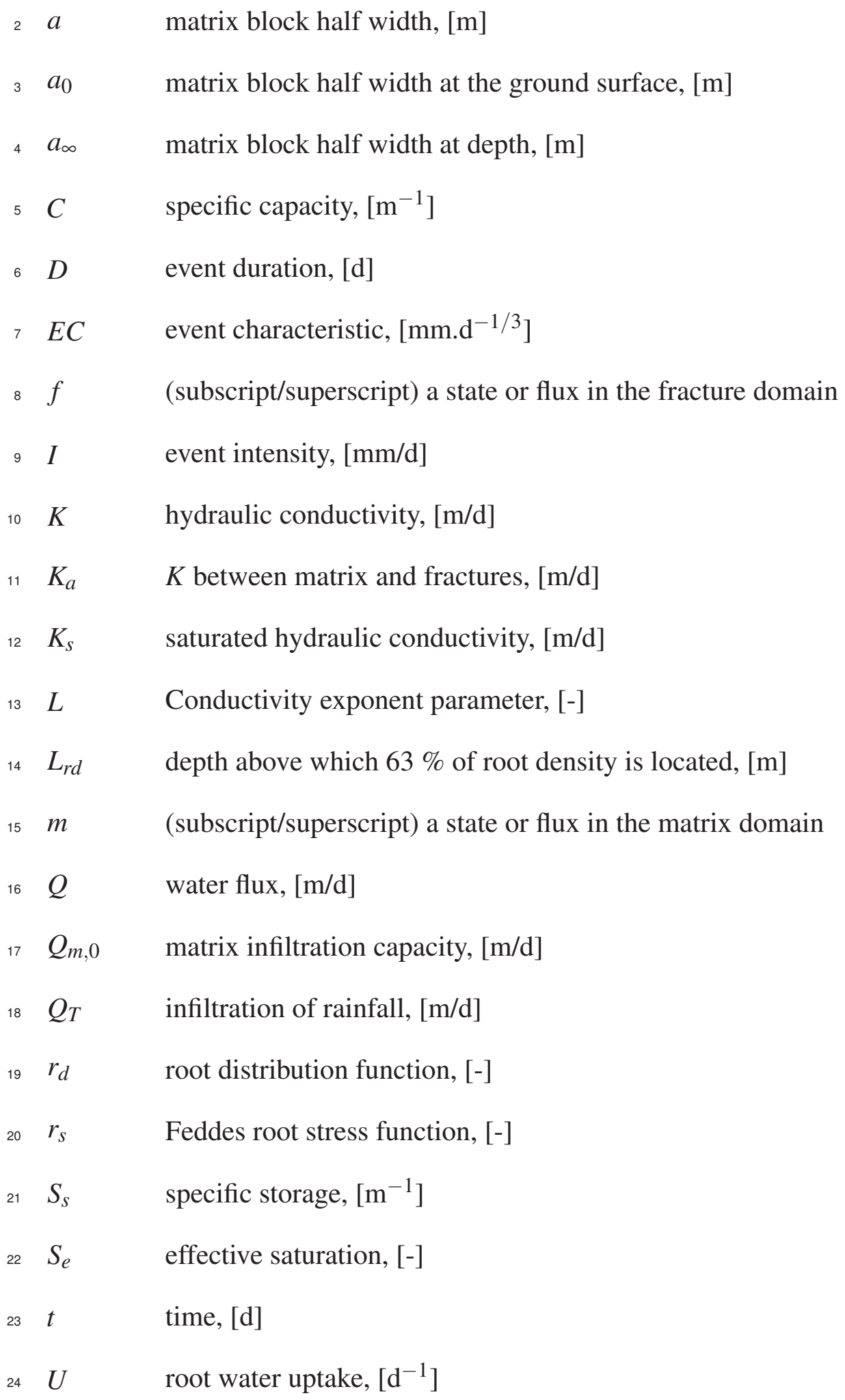




\begin{tabular}{|c|c|c|}
\hline 5 & $V$ & event volume, $[\mathrm{mm}]$ \\
\hline 6 & $w_{f}$ & fracture domain volume fraction, [-] \\
\hline 7 & $w_{f, 0}$ & fracture domain volume fraction at the ground surface, $[-]$ \\
\hline 8 & $w_{f, \infty}$ & fracture domain volume fraction in the deep Chalk, [-] \\
\hline 9 & $z$ & depth below ground level, $[\mathrm{m}]$ \\
\hline 0 & $z_{\alpha}$ & CUZ model shape parameter, $\left[\mathrm{m}^{-1}\right]$ \\
\hline 1 & $z_{\beta}$ & CUZ model shape parameter, $[\mathrm{m}]$ \\
\hline 2 & $\beta$ & matrix block geometry factor, [-] \\
\hline 3 & $\gamma_{w}$ & empirical coefficient for fracture-matrix exchange, [-] \\
\hline 4 & $\Gamma_{w}$ & Fracture-matrix exchange term, $\left[\mathrm{d}^{-1}\right]$ \\
\hline & $\theta$ & volumetric moisture content, $\left[\mathrm{m}^{3} / \mathrm{m}^{3}\right]$ \\
\hline & $\theta_{s}$ & saturated water content, $\left[\mathrm{m}^{3} / \mathrm{m}^{3}\right]$ \\
\hline 7 & $\theta_{r}$ & residual water content, [-] \\
\hline & $\sigma$ & Kosugi parameter, $[\mathrm{m}]$ \\
\hline & $\psi$ & matric potential, $[\mathrm{m}]$ \\
\hline & $\psi_{0}$ & Kosugi parameter, $[\mathrm{m}]$ \\
\hline 1 & $\psi_{1, \infty}$ & modified Kosugi model parameter, $[\mathrm{m}]$ \\
\hline 2 & $\psi_{1,0}$ & modified Kosugi model parameter, $[\mathrm{m}]$ \\
\hline 3 & $\psi_{2}$ & modified Kosugi model parameter, $[\mathrm{m}]$ \\
\hline 4 & $\psi_{a n}$ & matric potential threshold for anaerobiosis,$[\mathrm{m}]$ \\
\hline & $\psi_{d}$ & matric potential below which plant water stress begins, $[\mathrm{m}]$ \\
\hline & $\psi_{w}$ & wilting point, expressed as a matric potential, [m] \\
\hline
\end{tabular}


In unconfined aquifers, recharge is here defined as the time varying flux of water which passes from the base of the unsaturated zone into the saturated zone, with the water table marking the boundary between the two (Rushton, 1997; Scanlon et al., 2002). Over sufficiently long periods of time, the recharge volume will equal the volume of infiltrated rainfall minus evapotranspiration, termed here as effective rainfall. On shorter time scales (sub-annual) it is harder to quantify recharge, due to the attenuation of effective rainfall by storage in the unsaturated zone, which becomes more significant for increasingly shorter time scales. For example, on a daily time scale, the volume of recharge on a particular day is likely, especially under non-extreme rainfall conditions, to bear no relation to the volume of rain that fell that day. Therefore, as well as difficulties associated with the accurate spatiotemporal measurement of rainfall and evapotranspiration which can affect the total volume of recharge, quantifying the timing, of recharge also presents a significant challenge. Furthermore, in fractured porous media, such as the Chalk, the timing and volume of recharge in response to effective rainfall can be highly nonlinear due to the activation of fracture pathways (Lee et al., 2006; Ireson et al., 2009a). Groundwater resource assessment, which is a time integrated function of recharge, is generally less sensitive to recharge timing. Hence, in groundwater models used for this purpose, simple recharge models which are unable to resolve the timing of recharge, may still be suitable as long as they predict the long term volume of recharge with some degree of accuracy (note, there is some doubt that these model are able to do even this under drought conditions, discussed by Ireson et al., 2009b). However, two examples of where recharge timing is important are contam- 
inant transport (e.g. Brouyère, 2006; Jackson et al., 2007; Gooddy et al., 2007), and groundwater flooding (reviewed by Hughes et al., 2010). Habets et al. (2010) compared four different types of model for reproducing the groundwater flooding in the Somme catchment in 2000/1. They found the models were able to reproduce the spatial extent of flooding reasonably well. However, none of the models were able to reproduce the piezometric heads during and after the flooding. They attributed this to the overly simplistic representation of the unsaturated zone flow processes, in particular, the changing depth of the unsaturated zone, and the activation of preferential recharge through the fractures.

Understanding and quantification of recharge processes in Chalk aquifers in the UK, focussing in particular on the relative roles of the fractures and the porous matrix, have developed over 40 years (reviewed by Ireson et al., 2009b). Various conceptual models for how water moves within and between the matrix and fractures in the Chalk unsaturated zone have been proposed, with perhaps the most significant contributions from Wellings and Bell (1980), Price et al. (2000) and Haria et al. (2003). Recent work has focussed on the development of physically based models (Mathias, 2005; Mathias et al., 2006) and combining these with field observations (Brouyère, 2006; Van den Daele et al., 2007; Ireson et al., 2009b). In addition, workers have tried to infer preferential recharge mechanisms from rainfall-water table response data (Lee et al., 2006; Ireson et al., 2009a). Using interpretations from field data, Ireson et al. (2009a) have suggested that the activation of the fractures does not necessarily mean that there will be a rapid $(i 1 \mathrm{~d})$ recharge response (see their Figures 2 and 4). Partial wetting of the fractures can occur by the mechanisms described by Price et al. (2000) and Haria et al. (2003), and result in recharge 
responses which lag effective rainfall by tens of days (Ireson et al., 2009a). In this paper we concentrate on preferential recharge, by which we mean flow through the fractures which results in a rapid $(i 1 \mathrm{~d})$, highly non-linear recharge response, and not simply fracture flow (which may or may not be rapid). We develop work presented in two earlier papers, Ireson et al. (2009a) and Ireson et al. (2009b). Extended data sets have become available from the instrumented field sites in the Pang and Lambourn catchments, Berkshire, UK (described in Section 2), covering periods of extreme high and low rainfall conditions. We address limitations in the previously developed CUZ model (Ireson et al., 2009b) in the context of rapid preferential recharge under extreme high intensity rainfall. Empirical insights into controls on preferential recharge in the Chalk (Section 3) are combined with insights from an improved physically-based model (Section 4). In the discussion (Section 5), we draw together the findings from these two approaches to provide insights into controls on preferential recharge to Chalk aquifers.

\section{Field sites studied}

This study makes use of updated data sets from the Pang and Lambourn catchments, (Berkshire, UK, Fig. 1) collected partly under the NERC LOCAR programme, as well as additional instrumentation installed in the catchments, supplied by the FLOOD1 project (run jointly by BRGM, Orleans, the BGS and the University of Brighton, and partly funded by the EU INTERREG IIIA initiative). Previous studies (Ireson et al., 2006, 2009b) looked at recharge sites at Warren Farm (SU 3655 8092, depth to water table $\approx 40 \mathrm{~m}$ ) and West Ilsley (SU 484836 depth to water table $\approx 70 \mathrm{~m}$ ), located on the Seaford Chalk formation, with thin soils and 
deep unsaturated zones. These sites were instrumented to measure water content, $\theta[-]$, and matric potential, $\psi[\mathrm{m}]$, over a series of depths down to $4 \mathrm{~m}$, with readings logged every 15 minutes. Unfortunately the West Ilsley site was discontinued beyond 2004. However, in 2005, under FLOOD1, deep jacking tensiometers and piezometers were installed in a borehole at East Ilsley (SU 4996 8114, depth to water table $\approx 20 \mathrm{~m}$ ), located lower down the catchment, in the Pang Valley. In this paper we therefore focus on data from Warren Farm (WF) and East Ilsley (EI) (Figure 1).

\section{Figure 1.}

A complete summary of instrumentation used in this study are given in Table 1.

Table 1.

\section{Insights into preferential recharge from field data}

Previously, Ireson et al. (2009a) used data obtained from the deep jacking tensiometers and piezometer at East Ilsley, combined with sub-hourly tipping bucket raingauge data, to gain insights into Chalk recharge processes. It was suggested that three modes of recharge are active in the Chalk, under different effective rainfall conditions, as summarised in Table 2. Figure 2 shows the cumulative effective rainfall versus water table elevation at East Ilsley. During the low rainfall conditions in 2005/6 (as shown by the relatively shallow slope in effective rainfall, ER) recharge is via the matrix, with lags between peaks and troughs of $>100$ days (Ireson et al., 2009 a). In the winter of $2006 / 7$ the water table rises more markedly, in response to 
around $500 \mathrm{~mm}$ of effective rainfall over about 6 months, and lags of the order of tens of days were reported (Ireson et al., 2009a). On 20th July 2007, a large rainfall event (about $90 \mathrm{~mm}$ in 12 hours) caused a rapid (within 13 hours) and significant ( $>1 \mathrm{~m}$ water table rise) response. Following this event, the water table responded before the matric potential in the unsaturated zone immediately above the water table, shown in Figure 3. Therefore, this was interpreted as a preferential recharge event, with flow transmitted through the fractures, bypassing the matrix (Ireson et al., 2009a). As well as the immediate response, the water table continued to rise for one month following the event (we return to this observation in Section 4.3). This led to a high antecedent water level at the beginning of the recharge period for 2007/8. Sustained high rainfall during the summer of 2008 (CEH/Met Office, 2008) resulted in a continual rising trend in effective rainfall throughout this year, but despite this the water table dropped fairly steadily from March to September.

Table 1.

Figure 2.

In this paper, we focus on preferential recharge responses, such as the 20th July 2007 event. By close visual inspection of the water table data, a number of preferential responses to rainfall were identified by Ireson et al. (2009a). Here, we extend this analysis to cover a three year period up to September 2008. We define a rainfall event as a cluster of non-zero rainfall measurements (on an hourly time step) containing no gaps of longer than 6 hours, as shown in Figure 3. 536 events were identified in the three year record, with durations from 1 hour to $>2$ days and mean intensities from 1.2 to $180 \mathrm{~mm} / \mathrm{d}$. 18 of these rainfall events were followed within 24 hours by a perturbation of the water table, as determined by visual in- 
spection (referred to as "events perturbing the water table"). The duration, $D$, and mean intensity, $I$, of each rainfall event is shown in Figure 4, and events perturbing the water table are highlighted. As before, it was possible to partition the parameter space in this plot into three regions: events for which preferential recharge is highly unlikely to occur (region A); events for which preferential recharge may or may not occur (region B); and events for which preferential recharge is highly likely to occur (region C). The boundary between regions B and C was subtly moved from the previous location (Ireson et al., 2009a) to maximise the number of events perturbing the water table in region $\mathrm{C}$, but the gradient of this line was kept the same, i.e. $-2 / 3$ on a log-log plot. In addition, following the updated analysis, one anomalous point was found in region C (i.e. a point for which no water table response was observed). Nonetheless, this appears to be a reasonably robust method for predicting the onset of preferential recharge. It must be noted, however, that this is a site specific and subjective analysis, and it has not been demonstrated whether or not the method can be applied elsewhere, or the results can be generalised. In particular, this analysis has identified events that give rise to an observed water table response at a depth of around $20 \mathrm{~m}$ at this EI site. It is certainly possible that events that did not produce a water table response within a day at this site could have caused rapid preferential flow at smaller unsaturated depths, that was subsequently attenuated by storage in the fracture domain. Likewise, events that did cause a response at $20 \mathrm{~m}$ depth might not have caused a response at greater unsaturated depths.

Figure 3.

Figure 4.

The information in the left hand plot in Figure 4 can be presented as a single para- 
metric measure, which we call the "event characteristic", $E C$. Every point on this $\log -\log$ axis plot is translated along a path of gradient $-2 / 3$ onto the intercept (i.e. where the event duration is $10^{0}=1$ day), and then the exponential is taken, to give the $E C$, that is,

$$
\log (I)=-2 / 3 \cdot \log (D)+\log (E C)
$$

and hence

$$
E C=I . D^{2 / 3}=V \cdot D^{-1 / 3}
$$

where $V$ is the event volume $(I \times D)$. It can thus be seen that the event characteristic is a non-linear combination of intensity and duration (or volume and duration), with units of mm.d $\mathrm{d}^{-1 / 3} . E C$ for each event is plotted on the right hand side in Figure 4. Note, the event on 20th July 2007, which caused by far the largest water table response, has the largest $E C$, by a factor of about 2 . These results suggest that for East Ilsley an $E C$ of greater than $26.3 \mathrm{~mm} \cdot \mathrm{d}^{-1 / 3}$ will cause a preferential recharge response and an $E C$ of less than $8.3 \mathrm{~mm} \cdot \mathrm{d}^{-1 / 3}$ will not, irrespective of any other factors. For events within region $\mathrm{B}$, that is with an $E C$ between 8.3 and $26.3 \mathrm{~mm} \cdot \mathrm{d}^{-1 / 3}$, some other explanatory variable is required to predict whether or not preferential recharge will occur. In Figure 5, observed soil moisture storage in the top $60 \mathrm{~cm}$ of the unsaturated zone is plotted, with region $\mathrm{B}$ and $\mathrm{C}$ rainfall events highlighted. Unfortunately, soil moisture measurements were only available up to March 2007. It can be seen that there is no apparent relationship between soil moisture storage and occurrence of region $\mathrm{C}$ events. However, region B events only occur when the soil moisture storage is high, suggesting that under these rainfall 
conditions, the onset of preferential recharge also depends on the wetness of the soil/Chalk. We also looked at the antecedent water table depth, but no such relationship with region $\mathrm{B}$ events was apparent. We therefore suggest that the $E C$ and antecedent soil moisture can be used to determine the onset of preferential recharge, but it is highly likely that the thresholds in each will be site specific.

Figure 5.

\section{Modelling of recharge in the Chalk}

\subsection{Performance of the previous CUZ model}

Previously, a physically-based model for the CUZ (Ireson, 2008; Ireson et al., 2009b) was developed, which treated the matrix and fractures as an equivalent continuum (i.e. assuming instantaneous exchange between the domains), as first proposed by Peters and Klavetter (1988), and consistent with other flow models for the Chalk (Chapter 4 of Mathias, 2005; Brouyère, 2006). Hereafter, we refer to this model as the ECM model. This model included a novel means of representing near surface progressive weathering of the Chalk by relating hydraulic properties to pore size distributions (after Kosugi, 1996) and matrix/fracture domain fractions both of which evolve with depth. The model was successfully applied to reproduce near surface measurements of water content and matric potential at Warren Farm, calibrated using data from 2004 and validated using data from 2005. Since this work was published, more data have become available, both from the instruments used in that study at the Warren Farm recharge site and from additional instruments in- 
stalled in the Pang catchment. The previous period studied (2004/5) was a period of significant drought (Ireson et al., 2009a), whereas subsequent years were significantly wetter, and include an extreme high intensity rainfall event in the summer of 2007 (described above in Section 3).

The model was re-applied to an extended data set (covering 2004-7) at the same site, with no modifications to the parameters or model structure. The model was driven with rainfall data from a tipping rain gauge, and two separate estimates of evapotranspiration, all of which were measured at Warren Farm (approximately $300 \mathrm{~m}$ from the soil moisture instrumentation). As in the previous study, hourly actual evapotranspiration, AE, measured by eddy flux correlation was available (described in Ireson et al., 2009b). This direct measurement accounts for the effects of atmospheric demand, plant resistances (notably aerodynamic canopy resistance and stomatal resistance) and soil water stress on evapotranspiration. Also available from the automatic weather station were hourly meteorological variables (atmospheric pressure, humidity, temperature, net short and net long wave radiation) and soil heat flux, required to calculate potential evapotranspiration, $\mathrm{PE}$, for a reference grass crop (Allen et al., 1994). Land use at the site was grass throughout this period. These two local estimates of evapotranspiration differed somewhat in certain periods, most notably 2004/5, which allows us to explore the impact of uncertainty in the driving data. In both cases, following Ireson et al. (2009b), a modified version of the Feddes et al. (1976) model for distributing root water uptake was applied, such that the effect of soil water stress is to re-distribute root water uptake, but not reduce it. The locations of these instruments are given in Table 1.

The results of the updated model runs are shown in Fig. 6 for matric potential and 
water content change at $1 \mathrm{~m}$ depth, where the full range of conditions in each was measured comprehensively (Ireson et al., 2006). In addition, the figure shows simulated matrix and fracture fluxes at $15 \mathrm{~m}$ below ground level, assuming these to be indicative of the recharge to a water table just below this depth, such as at East Ilsley. For reference, the occurrences of observed water table response attributed to rapid preferential flow events at East Ilsley are also shown. For the period 2004/5, the model driven with AE is identical to the model in Ireson et al. (2009b), and reproduces water content and matric potential well during this period. Subsequently, however, this model fails to reproduce the wetting up in early 2006, and hence continues to underestimate the soil moisture state until early 2007. Attempts to recalibrate the model for the 2006 period all failed - no parameter set was found which could encompass the observations during this period, suggesting that either the driving data or the model structure were erroneous. Driving rainfall data were found to be consistent with surrounding gauges and Met Office radar data (NIMROD), and using alternative gauges was found to have only a minor effect on the model output. However, the driving evapotranspiration data were found to have a significant impact, and by using calculated PE, a quite different response was obtained. The PE driven model tended to perform better at reproducing the change in water content over the entire period where observations were available (20042007), but the matric potential was now overestimated in 2004/5. We are unable to comment upon which evapotranspiration data set is more accurate, but the finding that the model is highly sensitive to these differences is important. Evapotranspiration is in general difficult to measure, and even more difficult to validate, and, especially in areas where evapotranspiration makes up a large portion of the water balance, uncertainties in evapotranspiration associated both with climatic variables 
(e.g. Chun et al., 2009) and vegetation characteristics (Beven, 1979), will have a significant impact on hydrological predictions. In the context of using inverse modelling to identify hydraulic properties, as in this study, these uncertainties alone mean that meaningful identification of an optimal parameter set is not possible (we return to this issue below).

There was also a significant difference in the simulated recharge fluxes with each model. For the PE driven model, unlike the AE driven model, recharge through the fractures was simulated in the winters of 2004/5, 2006/7 and 2007/8. Neither model simulated fracture flow when we expected it to occur during the summer of 2007, following an extreme high intensity rainfall event, but both simulate fracture flow during the summer of 2008 (when sustained rainfall totals were high). In both cases, whenever fracture recharge is simulated, it persists for months. Therefore, the ECM is not able to the reproduce the discrete preferential recharge responses to high intensity rainfall that we expect to occur on the basis of the previous analysis.

Figure 6.

At $1.0 \mathrm{~m}$ depth, the pressure transducer tensiometer and equitensiometer provide a continuous record of matric potential over the entire range of field conditions. Combined with the profile probe data, it is possible to investigate the soil moisture characteristic (SMC) relationship at this depth, as shown in Figure 7. The elongated and inverted s-shape of this curve demonstrates the role of the fractures (wetting up at high matric potentials) and matrix (remaining saturated down to around $-15 \mathrm{~m}$, and draining at matric potentials below this). A notable feature of the SMC is that it appears to exhibit significant hysteresis. The SMC representation in the ECM model fits the primary drying curve of this observed data. To demonstrate further 
how significant this hysteresis was likely to be, quantile mapping (Hashino et al., 2007) was used to generate a time series of water content from matric potentials. The result in Figure 8 shows inconsistencies between the two data sets, most notably in the summer of 2004 and winter of 2006 . Hence any model assuming a constant relationship between $\theta$ and $\psi$, such as in the ECM model shown in Figure 7, would be unable to reconcile the observations in these two periods. This is also when the two models driven with different evapotranspiration data performed differently.

Figure 7.

Figure 8.

We therefore conclude that the structure of the ECM model is inadequate, especially in the context of predicting preferential responses. In the following sections the development and assessment of an improved model is described.

\subsection{Development of an improved CUZ model}

The classic cause of hysteresis in wetting and drying soils is the "ink-bottle" effect (Hillel, 1998). Modelling flow in hysteretic single porous media is extremely challenging, and whilst various methods have been proposed (e.g. Mualem, 1974; Pham et al., 2005), the authors are unaware of any models having been successfully applied to reproduce field observations. This is probably because of the challenge of parameterising the hysteretic relationships, in particular the $K(\psi)$ relationship, which cannot be observed. However, the Chalk is not a single porous media, and we postulate an alternative cause of the apparent hysteresis, which is that it is caused 
by: $i$ ) pressure disequilibrium between the fracture and the matrix domain, especially following infiltration from a rainfall event which would wet the fractures before the matrix; and ii) the fact that the instruments for measuring water content and matric potential sample different volumes of rock. Both neutron probes and profile probes take an integrated reading of water content over some volume of rock, with a minimum radius of about $0.1 \mathrm{~m}$. It is therefore likely that these readings are representative of the bulk fracture-matrix water content (especially in the weathered zone), as discussed by Ireson et al. (2006). Tensiometers and equitensiometers, on the other hand, sample at a point scale (or more accurately, over the contact area between the instrument tip and the rock). The tensiometer tip is likely to be located in a fracture (either natural or caused by the installation), but also in contact with the face of the matrix block. Therefore, we might expect a tensiometer to respond to a rapid increase in pressure in the fracture domain, but not to dry out below the pressure in the matrix. Thus, when the Chalk is dry, following a rainfall event the "fractures" (which in the near surface are enhanced by weathering) may wet up, causing a small increase in the bulk water content, but a large increase in the fracture pressure, thereby giving rise to the apparent scanning curves present in Fig. 7.

To model this effect, it is necessary to relax the assumption of instantaneous equilibrium between the fracture and matrix domains, central to the ECM approach. The simplest way to do this is to use a Dual Continua Modelling, DCM, approach (Doughty, 1999). In DCM models flows in the fracture and matrix domain are modelled separately, and exchange between these domains is governed by a first order transfer function. This adds at least one additional model parameter, but the major 
cost is that the numerical model is significantly more computationally expensive (having effectively doubled the number of nodes). However, the benefit of such a model is that, unlike the ECM, it allows us to simulate preferential flow in the fractures, which bypasses the matrix.

We adopt the DCM structure proposed by Gerke and van Genuchten (1993a), (GVG hereafter). In this model the dependent variables are the matric potential in the fractures, $\psi_{f}$, and matrix, $\psi_{m}$, and flow in each domain, governed by Richards' equation, is modelled separately

$$
\begin{aligned}
& \left(1-w_{f}\right)\left(S_{e, m} S_{s, m}+C_{m}\right) \frac{\partial \psi_{m}}{\partial t}=\frac{\partial}{\partial z}\left(\left(1-w_{f}\right) K_{m}\left[\frac{\partial \psi_{m}}{\partial z}-1\right]\right)+\Gamma_{w}-U_{m} \\
& w_{f}\left(S_{e, f} S_{s, f}+C_{f}\right) \frac{\partial \psi_{f}}{\partial t}=\frac{\partial}{\partial z}\left(w_{f} K_{f}\left[\frac{\partial \psi_{f}}{\partial z}-1\right]\right)-\Gamma_{w}-U_{f}
\end{aligned}
$$

Note here that as in Ireson et al. (2009b), specific capacity, $C$, and hydraulic conductivity, $K$, for each domain are a function of depth (using the relationships given in the Appendix), to account for changes in properties in the soil and weathered Chalk layers. The local exchange of water between the domains is governed by

$$
\Gamma_{w}=\frac{\beta \gamma_{w} K_{a}}{a^{2}}\left(\psi_{f}-\psi_{m}\right)
$$

where $\beta=3$ for rectangular matrix blocks, $\gamma_{w}$ was empirically determined to be 0.4 (GVG), and $a$ (the matrix half block width) and $K_{a}$ (the hydraulic conductivity governing exchange between the fractures and matrix) are to be determined. $K_{a}$ was defined as a function of matric potential using the same relationship as $K_{m}$ (see Appendix), but with a modified saturated hydraulic conductivity, $K_{s}^{a}$, to be determined. We would expect the matrix block size to be smaller in the shallow, weathered Chalk than in the deep consolidated Chalk (see Figure 1 in Ireson et al., 
2009b). The progressive weathering of the Chalk was characterised in the previous study using the relationships given in the Appendix that scale the pore size distribution of the fracture domain, and the domain fractions of the fractures and matrix, as a function of depth. In the DCM model the same scaling relationship is applied to the matrix block half width, $a$ :

$$
a=a_{\infty}+\frac{a_{0}-a_{\infty}}{1+\exp \left(z_{\alpha}\left(z-z_{\beta}\right)\right)}
$$

where $a_{0}$ is the matrix block half width at the ground surface, and $a_{\infty}$ is the matrix half width at depth. Hence, according to Equation 4, the rate of exchange between the fractures and the matrix would be larger in the near surface than at depth.

Infiltration of precipitation forms the upper boundary condition, which is prescribed as a flux into the fractures, $Q_{T, f}$, and matrix, $Q_{T, m}$. As in the GVG model, infiltration is assumed to occur into the Chalk matrix until its infiltration capacity, $Q_{m, 0}$, is exceeded. The infiltration capacity is determined using Darcy's law, where the hydraulic conductivity, $K_{m}^{*}$, and hydraulic gradient are found assuming that the matric potential in the matrix at the soil surface, $\Psi_{m, 0}^{*}$, is zero. Hence

$$
Q_{m, 0}=\left(1-w_{f}\right) K_{m}^{*}\left(\frac{\psi_{m, 1}-\psi_{m, 0}^{*}}{\Delta z}-1\right)
$$

where subscripts 0 and 1 refer to the soil surface and first node below the soil surface, respectively. This is equivalent to allowing infiltration to bring the matrix up to the point of saturation, but not beyond it to cause ponding. If the infiltration capacity is exceeded, the excess infiltrates into the fractures, whose infiltration capacity is sufficiently high that ponding or overland flow cannot occur. This is a reasonable 
${ }_{393} Q_{T, m}= \begin{cases}P, & P \leq Q_{m, 0} \\ Q_{m, 0}, & P>Q_{m, 0}\end{cases}$

$Q_{T, f}= \begin{cases}0, & P \leq Q_{m, 0} \\ P-Q_{m, 0}, & P>Q_{m, 0}\end{cases}$

$$
U_{f}=\frac{r_{s}\left(\psi_{f}\right) r_{d}(z) w_{f}}{\int_{0}^{L} r_{s}\left(\psi_{m}\right) r_{d}(z)\left(1-w_{f}(z)\right) d z+\int_{0}^{L} r_{s}\left(\psi_{f}\right) r_{d}(z) w_{f}(z) d z} A E
$$


$r_{s}(\psi)= \begin{cases}0, & \psi>\psi_{a n} \\ 1, & \psi_{a n} \geq \psi>\psi_{d} \\ 1-\frac{\psi}{\psi_{w}-\psi_{d}}, & \psi_{d} \geq \psi>\psi_{w} \\ 0, & \psi_{w} \geq \psi\end{cases}$

405 and

${ }_{406} \quad r_{d}(z)=\frac{\exp \left(-z / L_{r d}\right)}{L_{r d}}$

$\psi_{a n}, \psi_{d}$ and $\psi_{w}$ are water stress thresholds, assumed to have values of $-0.5 \mathrm{~m}$, $-4 \mathrm{~m}$ and $-150 \mathrm{~m}$ respectively (Feddes et al., 1976). $L_{r d}$, the depth above which approximately two-thirds of plant root density is located, was kept at $0.2 \mathrm{~m}$.

As before, a fixed head water table at $40 \mathrm{~m}$ depth was used for the lower boundary condition of the model. This was, again, because actual water table fluctuations cannot be reproduced with a 1D model, and imposing an observed water table response on the system would be expected to bias deep simulated fluxes. We previously (Ireson, 2008; Ireson et al., 2009b) demonstrated that this approach is reasonable if the boundary is sufficiently deep compared with the depths where we are interested in reproducing the observed states and fluxes (in this case states in the top $1 \mathrm{~m}$ and fluxes at $15 \mathrm{~m}$ depth). $15 \mathrm{~m}$ depth was chosen because between September 2005 and September 2008 the water table at East Ilsley fluctuates within the range of $\approx$ 15 to $28 \mathrm{~m}$ BGL. 
The coupled system of equations is solved numerically in MATLAB using the method of lines. Standard finite difference approximations are used to assess the spatial derivatives, using a node centred grid. The hydraulic conductivity is estimated at block boundaries using the arithmetic mean (Parissopoulos and Wheater, 2006). The temporal derivatives are integrated using the MATLAB ordinary differential equation solver ode15s (Shampine and Reichelt, 1997). This employs an adaptive time grid to minimise numerical errors, and boundary conditions are applied on an hourly time step.

In summary, the new model includes one additional state variable, required at every node and an additional 3 parameters governing the exchange of water between the two domains, namely $a_{0}, a_{\infty}$ and $K_{s}^{a}$.

\subsection{Performance of the improved CUZ model}

Initially, parameters from the original model were kept, physically realistic values of $a_{0}$ and $a_{\infty}$ were adopted and, following Gerke and van Genuchten (1993b) $K_{s}^{a}$ was set to $K_{s}^{m} / 100$. However, we found it was necessary to modify some parameters in order to achieve good model performance. Since the model was computationally more demanding than the ECM model (taking about 30 minutes to run a 5 year simulation on an hourly time step with 50 nodes on an Intel X9650 $3 \mathrm{GHz}$ processor), the number of parameters had increased, and the uncertainty in driving data could not be resolved, it was not feasible to optimise the model parameters. Rather, we focused on obtaining a "refined" parameter set to demonstrate the potential of the model to reproduce observed system behaviour. This was achieved through manual calibration. In doing this, we used calculated PE data to drive the model, since 
this gave a better model fit to the observed change in water content using the ECM model (Figure 6). We also performed a model sensitivity study, described later, which looked at both parametric sensitivity and the effect of using the observed AE to run the model. The ECM model parameters from Ireson et al. (2009b), and the refined DCM model parameters, are shown in Table 3.

Table 3

\section{Near surface changes in soil moisture state}

The refined model did a reasonable job of reproducing the observed change in water content throughout the top $1.0 \mathrm{~m}$, as shown in Figure 9. At $1.0 \mathrm{~m}$ depth, the performance was subtly better than the ECM model driven with PE (the RMSE was 0.0143 as compared with 0.0146 ). If the observed soil moisture characteristic curve is interpreted as bulk water content against fracture matric potential then consistent behaviour is reproduced by the simulation, as shown in Figure 10. The precise form of this simulated hysteretic relationship was sensitive to parametric changes. We did not attempt to actually fit the observed scanning curves (since this was not the central focus of this study, but would merit further study). The simulated behaviour appears to support our hypothesis that the matric potential measured by tensiometers is not representative of the bulk fracture-matrix system.

This also implies that the assumption that the fractures and matrix will always be in pressure equilibrium (inherent in all previous ECM modelling approaches) is not strictly valid.

\section{Figure 9}

Figure 10 
The simulated recharge fluxes (that is, fluxes at $15 \mathrm{~m}$ depth in the profile) are shown in Figure 11. Overall, matrix recharge dominates, but there are four discrete preferential fracture recharge events in the period shown. Three of these coincide with observed water table responses at East Ilsley, which are also indicated in Figure 11. The largest observed water table response in July 2007, which had the largest $E C$, was also simulated as the largest preferential recharge response, with a peak intensity of almost $100 \mathrm{~mm} / \mathrm{d}$. The event with the second largest $E C$ was on the 27th May 2007, but no preferential recharge was simulated on this date. Furthermore, preferential recharge was simulated on 19th January 2007 in response to an event with an $E C$ of 16, when no response in the water table at East Ilsley was observed. This is a region B event characteristic, i.e. one that we would expect to give a response only if the antecedent soil moisture was wet. These limitations are not surprising given that a model conditioned on data at one field site (Warren Farm) is being applied to try to reproduce observed responses at another (East Ilsley), that no rigourous model calibration was possible, and that, as already discussed, there are significant uncertainties in the driving data.

\section{Figure 11}

\section{Consistency of recharge-water table response}

The recharge fluxes transmitted through the matrix (Figure 11) follow a pattern which appears reasonably consistent with the water table response at East Ilsley (Figure 2), and is certainly an improvement over the ECM fluxes (Figure 6). The recharge fluxes slightly lag the water table response, but this is not necessarily an 
inconsistency. The water table response may be caused by the lateral propagation through the saturated zone of recharge reaching the water table earlier in the valleys where the unsaturated zone is thinner. Likewise, the continual rise of the water table at East Ilsley following the 20th July 2007 preferential recharge event might be caused by the delayed impacts of this recharge event reaching the water table under the interfluves (where the unsaturated zone is thicker) later, again propagated laterally through the saturated zone. This is speculation at this stage, and to make further insights it will be necessary to perform $2 \mathrm{D}$ or $3 \mathrm{D}$ modelling of the couple unsaturated/saturated zone.

In summary, the DCM modelling approach, whilst computationally demanding and hard to calibrate, is able to simulate the observed behaviour of the CUZ: specifically the near surface changes in water content, apparently hysteretic near surface soil moisture characteristic curves, and deep preferential recharge fluxes consistent with the types of water table responses that have been observed.

\subsection{Model sensitivity}

The DCM model has 22 hydraulic parameters, all of which have some physical meaning, and can therefore be placed into three categories: Conductivity parameters; Storage parameters; and Exchange parameters (governing the exchange of water between the fracture and matrix domains). A sensitivity study was performed, considering each of these three separately. An important finding during the manual calibration exercise was that the exchange parameters and the fracture storage parameters had a relatively small impact on the near surface changes in water content, but a highly significant impact on the deep fluxes. In this sensitivity study, 
where the focus is on controls on preferential recharge, we concentrate on the sensitivity of the deep fluxes. The previously refined model driven with PE is taken as the benchmark (parameters are given in Table 3), and the impact of modifications to certain parameters, or groups of parameters, on the relative amount of bypass recharge are summarised in Table 4, and discussed below.

Table 4.

\section{Conductivity parameters}

As for the ECM model, in our judgement the most sensitive parameter in the DCM model was the matrix saturated hydraulic conductivity, $K_{s}^{m}$. The effect of changes in this parameter on fracture and matrix fluxes is shown in Figure 12. As $K_{s}^{m}$ increases then a larger proportion of the infiltrating flux can be transmitted through the matrix, hence the matrix flux increases, and the fracture fluxes decrease in both magnitude and occurrence. Moreover, in the DCM model $K_{s}^{m}$ plays a key role in the partitioning of infiltration between the matrix and the fractures at the surface (see Equation 6). Particularly if the rate of exchange between the fractures and matrix is small, this might be the dominant control in the model on deep preferential recharge. These findings are reflected in Table 4, showing that when $K_{s}^{m}$ was doubled to $2 \mathrm{~mm} / \mathrm{d}$, no preferential recharge was simulated, whilst when it was halved to $0.5 \mathrm{~mm} / \mathrm{d}$ the volume of preferential recharge increased significantly.

Figure 12

The previous study found that the fracture saturated hydraulic conductivity, $K_{S}^{f}$, was only moderately sensitive over 3 orders of magnitude. In this study, the refined value for $K_{S}^{f}$ was increased to give a bulk saturated hydraulic conductiv- 
ity $\left(w_{f} K_{s}^{f}\right)$ consistent with values of Chalk saturated hydraulic conductivity (e.g. Williams et al., 2006). A value of $27,000 \mathrm{~m} / \mathrm{d}$, combined with an increase in the Mualem conductivity exponent parameter, $L$ to 14.3 , provided a reasonable performance, which for a fracture porosity of $0.1 \%$ (discussed below) is equivalent to a bulk Chalk saturated hydraulic conductivity of $27 \mathrm{~m} / \mathrm{d}$. The impact of increasing or decreasing $K_{s}^{f}$ by one order of magnitude was to increase or decrease, respectively, the volume of bypass flow, without significantly affecting the timing/onset. This would therefore be an important parameter in a coupled unsaturated zone/saturated zone model.

\section{Storage parameters}

Storage in the dual permeability, vertically heterogeneous, partially saturated soil/weathered Chalk/consolidated Chalk, is complex, being described by 13 parameters. These determine the volume of saturated storage and the rate at which storage reduces with reducing pore water pressure in each domain, and how these change with depth. Rather than performing a univariate sensitivity study, we looked separately at sensitivity to dynamic storage in the near surface and sensitivity to storage in the deep fractures. Storage in the matrix is less dynamic, and well characterised by the observed soil moisture characteristic data.

To explore sensitivity to changes in the soil at the surface, as well as the benchmark model (soil a), we considered four alternative soil/weathered Chalk layer configurations, denoted as soils b), c), d) and e), depicted in Figure 13. Each was achieved by parametric modifications shown in Table 5. Soils a), b) and c) all have the same volume of dynamic storage (that is, storage associated with the fracture/soil do- 
main), but this storage is distributed differently over depth. For a high porosity, shallow soil (b) and a low porosity deep soil (c) no bypass recharge was generated, in both cases because more water was able to pass from the fractures into the matrix. In soil b) this was because of an increased gradient between the domains as the shallow soil filled with water following infiltration. In soil c this was because of an increased depth over which exchange between the domains was possible. It should be noted that where the soil porosity is high, the matrix half block width is low, and hence exchange between the fracture and matrix domains is higher. More predictably, when the volume of dynamic near surface storage is reduced (d) there is less attenuation of infiltration in the near surface, and the incidence and magnitude of preferential recharge increases, and vice versa when the volume is increased (e). This demonstrates that there is a high sensitivity to both the volume and distribution of near surface storage. In fact, the profile used in the benchmark model was not modified from the previous ECM model, and was thus based on fitting the scaled Kosugi (1996) model for $\theta(\psi)$ to observed drying curves at $0.2,0.4,0.6$ and $1.0 \mathrm{~m}$ depth, as described in Ireson et al. (2009b).

\section{Table 5.}

Figure 13.

The second most sensitive parameter in these experiments (after $K_{s}^{m}$ ) was the porosity of the deep fractures, $w_{f, \infty}$. A typical value from the literature (Price et al., 1993; Mathias et al., 2006) is 1\%, which was used in the previous study. This was found to be too large to generate deep preferential recharge (Table 4). Significantly improved results were obtained by reducing this by an order to magnitude to $0.1 \%$, as used in the benckmark model. Reducing this further to $0.01 \%$ led to an increase in 
bypass recharge, but might be harder to justify physically. The fact that such a low value was required in the model may in fact reflect the fact that not all of the deep fractures are activated (so called flow focussing, Bodvarsson et al., 2003). For a rock with an actual fracture porosity of $1 \%$, if only one in ten of the deep fractures is actually connected to the active infiltration pathways, this would be equivalent to an effective fracture porosity of $0.1 \%$ in an continuum representation of the system.

\section{Exchange parameters}

The exchange between fracture and matrix domains is governed by the head gradient between them, and a coefficient given by $\beta \gamma_{w} K_{a}(\psi) / a(z)^{2}$ (Equation 4). Here we explore how variations in this bulk coefficient affect the model by changing $K_{s}^{a}$ which, unlike the other parameters, might vary over orders of magnitude (hence uncertainties in the empirical $\beta$ and $\gamma_{w}$ parameters are negligible). We also explore how variations in the depth distribution of this bulk coefficient affect the model by changing $a_{0}$ and $a_{\infty}$.

When the coefficient is increased by an order of magnitude (by setting $K_{s}^{a}=K_{s}^{m} / 10$, see Table 4) there is more exchange between the domains, meaning that infiltration in the fracture domain is able to pass into the matrix domain, and preferential recharge is reduced. Likewise, if the coefficient is reduced by an order of magnitude (by setting $K_{s}^{a}=K_{s}^{m} / 1000$, see Table 4), less exchange between the domains led to an increase in preferential recharge. Therefore, $K_{s}^{a}$ is both a highly sensitive and highly uncertain parameter. Good results were obtained using $K_{S}^{a}=K_{S}^{m} / 100$, as used by Gerke and van Genuchten (1993b) in their experiments. However, but this was purely empirical and they noted that $K_{a}$ is a critical parameter, for which little 
is known about the physical or chemical properties. Therefore, accurately characterising $K_{a}$ for the Chalk is an outstanding and daunting challenge.

Changing the rate of exchange in the near surface, by modifying $a_{0}$ (see Table 4), has a relatively small impact on simulated preferential recharge. Changing the rate of exchange in the consolidated Chalk, by modifying $a_{\infty}$ (see Table 4 ), has a more significant impact, especially on the more moderate preferential recharge responses (i.e. not 20th July 2007), since this affects the exchange over a much larger depth. However, in general the sensitivity to modifications to the matrix block size, within physically realistic bounds, is small compared with changes to the bulk exchange coefficient associated with uncertainties in the $K_{a}$ parameter.

\section{Driving data}

As can be seen in Table 4 (benchmark versus AE model run) the impact of uncertainty in evapotranspiration driving data has a significant impact on the total proportion of preferential recharge, but a negligible impact on the recharge response to the extreme event on 20th July 2007. This is consistent with the finding in Section 3 that the response to this rainfall event was independent of antecedent soil moisture which would have been affected by differences in evapotranspiration. This is also consistent with the findings from the ECM model, and again highlights the importance of uncertainty in driving data when trying to model field observations. 


\section{Discussion}

In this paper we present two complementary approaches to assessing controls on preferential recharge to Chalk aquifers. In the first approach (Section 3), inferences are drawn from observations of rapid water table responses which coincide with particular rainfall events. We propose that a measure of the magnitude of the rainfall event, the event characteristic, is a good predictor of when large preferential recharge responses might occur. To predict responses to more moderate rainfall events, it is also necessary to take the antecedent soil moisture into account. Due to its simplicity, this is an attractive method for partitioning recharge, and could easily be implemented in any soil water balance based recharge model (e.g. Penman Grindley, Catchmod, QR Heathcote et al., 2004). However, this method has not yet been demonstrated for other sites, and it is likely that the thresholds associated with the onset of preferential recharge, in both the event characteristic and antecedent soil moisture, will be site specific.

This analysis requires hourly rainfall data in order to be able to characterise effectively the event characteristic. This demonstrates that the system is sensitive to sub-daily rainfall, which needs to be accounted for irrespective of the modelling approach adopted. Hourly rainfall observations from tipping bucket rain gauges are widely available in the UK. For assessing future climate impacts on recharge, projections of downscaled daily rainfall are widely available, but hourly data less so. For example UKCP09 does provide hourly rainfall generated using a weather generator, but this is based on downscaled daily data which has been temporally disaggregated (Jones et al., 2009) and it is unclear whether this has been adequately 
validated for the types of sub-daily extreme rainfall that are important for generating preferential recharge. Therefore, quantifying the future impacts of climate change on preferential recharge still presents a significant challenge.

The second approach in this paper (Section 4) focussed on the use of physically based models of the Chalk unsaturated zone to predict preferential recharge. A number of limitations in existing models developed for the CUZ were apparent. Most significant was the finding that an equivalent continuum representation of the matrix and fractures, which assumes instantaneous exchange of water between these two domains, is unsuitable for predicting deep fracture flow responses. The dual continua approach of Gerke and van Genuchten (1993a) appears better suited. This model can reproduce observed soil moisture states and apparently hysteretic soil moisture characteristics in the near surface, as well as the occurrence of preferential recharge responses at depth. The advantage of using such a physically based model over a simple recharge model, is that all of the parameters have a physical meaning, and whilst it is hard (perhaps not currently possible) to optimise these parameters, the impact of individual parametric modifications has a predictable effect on the model performance (as demonstrated in Section 4.4). As such, it is possible, using manual methods, to tailor the model to match observed system behaviour. For example, this could be useful in a situation where water table observations are available for two different boreholes with different unsaturated depths, where only the shallower one responds to a particular rainfall event. In this case, the $K_{S}^{f}$ and/or $K_{s}^{a}$ parameters could, in principle, be adjusted such that the fracture response is propagated as far as the first water table, but not as far as the second.

One inherent limitation with the one-dimensional model is that the water table re- 
sponse cannot be reproduced, since it also depends on lateral flow processes within the saturated zone. In Section 4.3, we speculate as to how the simulated recharge signal might be consistent with the water table response at East Ilsley, as a result of the earlier and later impacts of the recharge signal down slope and up slope, respectively. This appears a coherent interpretation, but to make further insights, 2 or 3 dimensional, coupled saturated-unsaturated flow modelling is required.

\section{Acknowledgements}

The authors are grateful to colleagues at Imperial College, Howard Wheater and Simon Parker; the British Geological Survey, including Chris Jackson, Denis Peach, Andrew Hughes, Thalia Vounaki and Alex Gallagher; and Jon Finch at the Centre for Ecology and Hydrology for their help and advice on the work presented here. Funding was provided by NERC through the Flood Risk from Extreme Events programme (NE/E002307/1). Data were provided by CEH and BGS, from the NERC LOCAR and EU FLOOD1 projects.

\section{References}

Allen, R. G., Smith, M., Pereira, L. S., Perrier, A., 1994. An update for the calculation of reference evapotranspiration. ICID 43 (2), 35-93.

Beven, K., 1979. A sensitivity analysis of the Penman-Monteith actual evapotranspiration estimates. Journal of Hydrology 44 (3-4), 169-190.

Bodvarsson, G. S., Wu, Y. S., Zhang, K., 2003. Development of discrete flow paths 
in unsaturated fractures at Yucca Mountain. Journal of contaminant hydrology $62,23-42$

Brouyère, S., 2006. Modelling the migration of contaminants through variably saturated dual-porosity, dual-permeability Chalk. J. Cont. Hydrol. 82, 195-219.

CEH/Met Office, 2008. http://www.nerc-wallingford.ac.uk/ih/nrfa/monthly_summaries/2008/09/rn00.pdf. Met Office, UK and Centre for Ecology and Hydrology, Wallingford, National Riverflow Archive.

Chun, K., Wheater, H., Onof, C., 2009. Streamflow estimation for six UK catchments under future climate scenarios. Hydrology research.

Doughty, C., 1999. Investigation of conceptual and numerical approaches for evaluating moisture, gas, chemical and heat transport in fractured unsaturated rock. J. Cont. Hydrol. 38, 69-106.

Feddes, R. A., Kowalik, P., Kolinska-Malinka, K., Zaradny, H., 1976. Simulation of field water uptake by plants using a soil water dependent root extraction function. Journal of Hydrology 31.

Gerke, H. H., van Genuchten, M. T., 1993a. A dual-porosity model for simulating the preferential movement of water and solutes in structured porous media. Water Resour. Res. 29 (2), 305-319.

Gerke, H. H., van Genuchten, M. T., 1993b. Evaluation of a first-order water transfer term for variably saturated dual-porosity flow models. Water Resour. Res. $29(2), 1225-1238$.

Gooddy, D. C., Mathias, S. A., Harrison, I., Lapworth, D. J., Kim, A. W., 2007. The significance of colloids in the transport of pesticides through Chalk. Science of the Total Environment 385 (1-3), 262-271.

Habets, F., Gascoin, S., Korkmaz, S., Thiéry, D., Zribi, M., Amraoui, N., Carli, M., 
Ducharne, A., Leblois, E., Ledoux, E., et al., 2010. Multi-model comparison of a major flood in the groundwater-fed basin of the Somme River (France). Hydrol. Earth Syst. Sci 14, 99-117.

Haria, A. H., Hodnett, M. G., Johnson, A. C., 2003. Mechanism of groundwater recharge and pesticide penetration to a chalk aquifer in southern England. J. Hydrol. 275, 122-137.

Hashino, T., Bradley, A. A., Schwartz, S. S., 2007. Multi-model comparison of a major flood in the groundwater-fed basin of the Somme River (France). Hydrol. Earth Syst. Sci 11 (2), 939-950.

Heathcote, J., Lewis, R., Soley, R., 2004. Rainfall routing to runoff and recharge for regional groundwater resource models. Quarterly Journal of Engineering Geology and Hydrogeology 37 (2), 113.

Hillel, D., 1998. Environmental Soil Physics. Academic Press, London.

Hughes, A., Vounaki, T., Peach, D., Ireson, A. M., Jackson, C., Butler, A., Finch, J., Wheater, H. S., 2010. Flood risk from groundwater: examples from in a Chalk catchment in southern England. Journal of Flood Risk Management - submitted. Ireson, A. M., 2008. Quantifying the hydrological processes governing flow in the unsaturated Chalk. Ph.D. thesis, Imperial College London.

Ireson, A. M., Butler, A. P., Gallagher, A., 2009a. Groundwater flooding in fractured permeable aquifers. In: IAHS Publication 330: Improving integrated surface and groundwater resource management in a vulnerable and changing world. IAHS/AISH, Chichester, pp. 165-172.

Ireson, A. M., Mathias, S. A., Wheater, H. S., Butler, A. P., Finch, J., 2009b. A model for flow in the Chalk unsaturated zone incorporating progressive weathering. J Hydrol. 365, 244-260. 
Ireson, A. M., Wheater, H. S., Butler, A. P., Mathias, S. A., Finch, J., Cooper, J. D., 2006. Hydrological processes in the Chalk unsaturated zone - insights from an intensive field monitoring programme. J Hydrol. 330, 29-43.

Jackson, B. M., Wheater, H. S., Wade, A. J., Butterfield, D., Mathias, S. A., Ireson, A. M., Butler, A. P., McIntyre, N. R., Whitehead, P. G., 2007. Analysis of waterlevel response to rainfall and implications for recharge pathways in the Chalk aquifer, SE England. Ecological Modelling 209, 604-620.

Jones, P. D., Kilsby, C. G., Harpham, C., Glenis, V., Burton, A., 2009. UK Climate Projections science report: Projections of future daily climate for the UK from the Weather Generator. Tech. rep., University of Newcastle, UK.

Kosugi, K., 1996. Lognormal distribution model for unsaturated soil hydraulic properties. Water resources research 32 (9), 2697-2703.

Lee, L. J. E., Lawrence, D. S. L., Price, M., 2006. Analysis of water-level response to rainfall and implications for recharge pathways in the Chalk aquifer, SE England. Journal of Hydrology 330, 604-620.

Mathias, S. A., 2005. Transient simulations of flow and transport in the Chalk unsaturated zone. Ph.D. thesis, Imperial College London.

Mathias, S. A., Butler, A. P., Jackson, B. M., Wheater, H. S., 2006. Transient simulations of flow and transport in the Chalk unsaturated zone. J Hydrol. 330, 10-28.

Mualem, Y., 1974. A conceptual model of hysteresis. Water Resour. Res. 10, 514 520.

Parissopoulos, G. A., Wheater, H. S., 2006. On numerical errors associated with the iterative alternating direction implicit (Iadi) finite difference solution of the two dimensional transient saturated-unsaturated flow (Richards) equation. Hydrological Processes 2 (2), 187-201. 
Peters, R. R., Klavetter, E. A., 1988. A Continuum Model for Water Movement in an Unsaturated Fractured Rock Mass. Water Resour. Res. 24 (3), 416-430.

Pham, H. Q., Fredlund, D. G., Barbour, S. L., 2005. A study of hysteresis models for soil-water characteristic curves. Canadian Geotechnical Journal 42 (6), 15481568.

Price, M., Downing, R. A., Edmunds, W. M., 1993. The Chalk as an aquifer. In: Downing, R. A., Price, M., Jones, G. P. (Eds.), The Hydrogeology of the Chalk of North-West Europe. Clarendon Press, Oxford.

Price, M., Low, R. G., McCann, C., 2000. Mechanisms of water storage and flow in the unsaturated zone of the Chalk aquifer. J. Hydrol. 233, 54-71.

Rushton, K., 1997. Recharge from permanent water bodies. In: I, S. (Ed.), Recharge of phreatic aquifers in (semi)arid areas. AA Balkema, Rotterdam.

Scanlon, B. R., Healy, R. W., Cook, P. G., 2002. Choosing appropriate techniques for quantifying groundwater recharge. Hydrogeology Journal 10 (1), 18-39.

Shampine, L. F., Reichelt, M. W., 1997. The Matlab ODE suite. SIAM J. Sci. Comput. $18(1), 1-22$.

Van den Daele, G. F. A., Barker, J. A., Connell, L. D., Atkinson, T. C., Darling, W. G., Cooper, J. D., 2007. Unsaturated flow and solute transport through the Chalk: Tracer test and dual permeability modelling. Journal of Hydrology 342, $157-172$.

Wellings, S. R., Bell, J. P., 1980. Movement of water and nitrate in the unsaturated zone of the Upper Chalk near Winchester, Hants., England. J. Hydrol. 48, 119136.

Williams, A., Bloomfield, J., Griffiths, K., Butler, A., 2006. Characterising the vertical variations in hydraulic conductivity within the Chalk aquifer. Journal of 


\section{Appendix: Hydraulic properties}

806

$$
x_{1}=-\sqrt{2}\left(\operatorname{erf}^{-1}[2 \times 0.05-1]\right)
$$

where

and

$$
\begin{aligned}
\sigma & =\frac{\ln \left(\frac{\psi_{2}}{\psi_{1}}\right)}{x_{2}-x_{1}} \\
\psi_{0}=5 & =\frac{\psi_{1}}{e^{\left(x_{1}+\sigma\right) \sigma}}
\end{aligned}
$$

$$
S_{e}=0.5+0.5 \operatorname{erf}\left(-\frac{\left[\ln \left(\psi / \psi_{0}\right) / \sigma-\sigma\right]}{\sqrt{2}}\right)
$$




$$
x_{2}=-\sqrt{2}\left(\operatorname{erf}^{-1}[2 \times 0.95-1]\right)
$$

${ }_{816} \quad w_{m}=1-w_{f}$

$$
w_{m}=1-w_{f}
$$

For the fracture domain only, the pore size distribution is modified as a function of depth, using the relationship

$$
\psi_{1}^{f}=\psi_{1, \infty}^{f}+\frac{\psi_{1,0}^{f}-\psi_{1, \infty}^{f}}{1+\exp \left(z_{\alpha}\left(z-z_{\beta}\right)\right)}
$$

The fracture domain fraction is also modified with depth using the relationship

$$
w_{f}=w_{f, \infty}+\frac{w_{f, 0}-w_{f, \infty}}{1+\exp \left(z_{\alpha}\left(z-z_{\beta}\right)\right)}
$$

and the matrix domain fraction is given by

${ }_{817}$ All symbols appearing here that are not given by one of these relationships are 818 parameters, listed in Table 3. 


\begin{tabular}{|l|l|l|l|l|}
\hline Variable & Site & Instrument & Frequency & Period \\
\hline Precipitation & WF & Tipping bucket raingauge & hourly & Sep 2003 - Sep. 2008 \\
Actual Evap. & WF & Eddy flux correlation & hourly & Sep 2003 - Sep 2007 \\
Potential Evap. & WF & Automatic weather station & hourly & Sep 2003 - Sep 2008 \\
Water content & WF & Profile probes ${ }^{1}(\leq 1.0 \mathrm{~m}$ BGL) & 15 min. & Jan 2004 - Mar 2007 \\
Matric potential & WF & Pressure transducer tensiometers $(\leq 1.2 \mathrm{~m}$ BGL) & 15 min. & Jan 2004 - Jan 2008 \\
Matric potential & WF & Equitensiometers $(1.0-4.0 \mathrm{~m}$ BGL) & 15 min. & Jan 2004 - Jan 2008 \\
Matric potential & EI & Deep jacking tensiometers (10 - 24 m BGL) & hourly & Sep 2005 - Jan 2008 \\
Water table & EI & Piezometer & hourly & Sep 2005 - Jan 2008 \\
\hline
\end{tabular}

1. Profile probes were calibrated against 2 weekly neutron probe readings, as described in

Ireson et al., 2006

Table 1

Instrumentation used in this study

\begin{tabular}{|c|c|c|}
\hline $\begin{array}{l}\text { Extreme low intensity } \\
\text { rainfall }\end{array}$ & $\begin{array}{l}\text { Non-extreme rain- } \\
\text { fall/Extreme long dura- } \\
\text { tion rainfall }\end{array}$ & $\begin{array}{l}\text { Extreme high intensity } \\
\text { rainfall }\end{array}$ \\
\hline $\begin{array}{l}\text { Continuous slow drainage } \\
\text { from the matrix; recharge } \\
\text { persists throughout } \\
\text { the summer (drought } \\
\text { resilience) }\end{array}$ & $\begin{array}{l}\text { Recharge via matrix and } \\
\text { partially saturated frac- } \\
\text { tures, lags of } 10 \text { s of days. } \\
\text { Cause of historic GW } \\
\text { flooding. }\end{array}$ & $\begin{array}{l}\text { Rapid bypass recharge, } \\
\text { through fractures, lags of } \\
<1 \text { day. Potential to con- } \\
\text { tribute to GW flooding. }\end{array}$ \\
\hline
\end{tabular}

Table 2

Modes of recharge in the Chalk (after Ireson et al., 2009) 


\begin{tabular}{|c|c|c|}
\hline \multirow[t]{2}{*}{ Parameter } & \multicolumn{2}{|c|}{ Parameter value } \\
\hline & original ECM & refined DCM \\
\hline$\theta_{r}^{m}$ & 0 & 0 \\
\hline$\theta_{s}^{m}$ & 0.35 & 0.35 \\
\hline$\theta_{r}^{f}$ & 0 & 0 \\
\hline$\theta_{s}^{f}$ & 1 & 1 \\
\hline$w_{f, 0}$ & 0.12 & 0.08 \\
\hline$w_{f, \infty}$ & 0.01 & 0.001 \\
\hline$a_{0}$ & - & $0.03 \mathrm{~m}$ \\
\hline$a_{\infty}$ & - & $1.0 \mathrm{~m}$ \\
\hline$\psi_{1}^{m}$ & $-95.2 \mathrm{~m}$ & $-95.2 \mathrm{~m}$ \\
\hline$\psi_{2}^{m}$ & $-14.1 \mathrm{~m}$ & $-14.1 \mathrm{~m}$ \\
\hline$\psi_{1,0}^{f}$ & $-40.1 \mathrm{~m}$ & $-40.1 \mathrm{~m}$ \\
\hline$\psi_{1, \infty}^{f}$ & $-1.29 \mathrm{~m}$ & $-1.29 \mathrm{~m}$ \\
\hline$\psi_{2}^{f}$ & $-0.1 \mathrm{~m}$ & $-0.1 \mathrm{~m}$ \\
\hline$K_{s}^{m}$ & $0.53 \mathrm{~mm} /$ day & $1.0 \mathrm{~mm} / \mathrm{day}$ \\
\hline$K_{s}^{f}$ & $2.83 \mathrm{~m} /$ day & $27000 \mathrm{~m} /$ day \\
\hline$K_{s}^{a}$ & - & $K_{s}^{m} / 100$ \\
\hline$L^{m}$ & 0.5 & 0.5 \\
\hline$L^{f}$ & 4.08 & 14.3 \\
\hline$z_{\alpha}$ & $1.4 \mathrm{~m}^{-1}$ & $1.4 \mathrm{~m}^{-1}$ \\
\hline$z_{\beta}$ & $0.89 \mathrm{~m}$ & $0.89 \mathrm{~m}$ \\
\hline$S_{s}^{m}$ & $10^{-6} \mathrm{~m}^{-1}$ & $10^{-6} \mathrm{~m}^{-1}$ \\
\hline$S_{s}^{f}$ & $10^{-6} \mathrm{~m}^{-1}$ & $10^{-6} \mathrm{~m}^{-1}$ \\
\hline
\end{tabular}

Table 3

Summary of all model parameters 


\begin{tabular}{|l|c|c|}
\hline Model run & Extreme event bypass & 2007 total bypass \\
\hline Benchmark & $9.6 \%$ & $7.0 \%$ \\
AE model run & $9.2 \%$ & $14.4 \%$ \\
\hline Sensitivity to hydraulic conductivity \\
\hline$K_{s}^{m}=0.002$ & $0 \%$ & $0 \%$ \\
$K_{s}^{m}=0.0005$ & $23.9 \%$ & $61.6 \%$ \\
$K_{s}^{f}=2700$ & $3 \%$ & $1.4 \%$ \\
$K_{s}^{f}=270000$ & $15.5 \%$ & $10.1 \%$ \\
\hline Sensitivity to storage & \\
\hline Soil b) & $0 \%$ & $0 \%$ \\
Soil c) & $0 \%$ & $0 \%$ \\
Soil d) & $43.9 \%$ & $21 \%$ \\
Soil e) & $0 \%$ & $0 \%$ \\
$w_{f, \infty}=0.01$ & $0 \%$ & $0 \%$ \\
$w_{f, \infty}=0.0001$ & $20.5 \%$ & $15.4 \%$ \\
\hline Sensitivity to fracture-matrix exchange & \\
\hline$K_{s}^{A}=K_{s}^{m} / 10$ & $1.60 \%$ & $0.70 \%$ \\
$K_{s}^{A}=K_{s}^{m} / 1000$ & $25.3 \%$ & $26.9 \%$ \\
$a_{0}=0.5$ & $8.7 \%$ & $7.3 \%$ \\
$a_{0}=0.003$ & $11.1 \%$ & $7.2 \%$ \\
$a_{\infty}=0.5$ & $2.5 \%$ & $1.2 \%$ \\
$a_{\infty}=2$ & $12.8 \%$ & \\
\hline
\end{tabular}

Table 4

Sensitivity of preferential recharge to different model configurations. Extreme event bypass is calculated as the volume of fracture flow on 20th July 2007, divided by the volume of rainfall on that day. 2007 total bypass is calculated as the volume of fracture flow in 2007 divided by the volume of fracture and matrix flow in 2007 . 


\begin{tabular}{|l|c|c|c|c|}
\hline Soil & $w_{f, \infty}$ & $w_{f, 0}$ & $z_{\alpha}$ & $z_{\beta}$ \\
\hline a) & 0.001 & 0.08 & 1.4 & 0.89 \\
b) & 0.001 & 0.113 & 30 & 0.8 \\
c) & 0.001 & 0.02 & 3 & 4.6 \\
d) & 0.001 & 0.01 & 1.4 & 0.89 \\
e) & 0.001 & 0.12 & 1.4 & 0.89 \\
\hline
\end{tabular}

Table 5

Parameters describing the different soil/weathered Chalk profiles used in Figure 13 


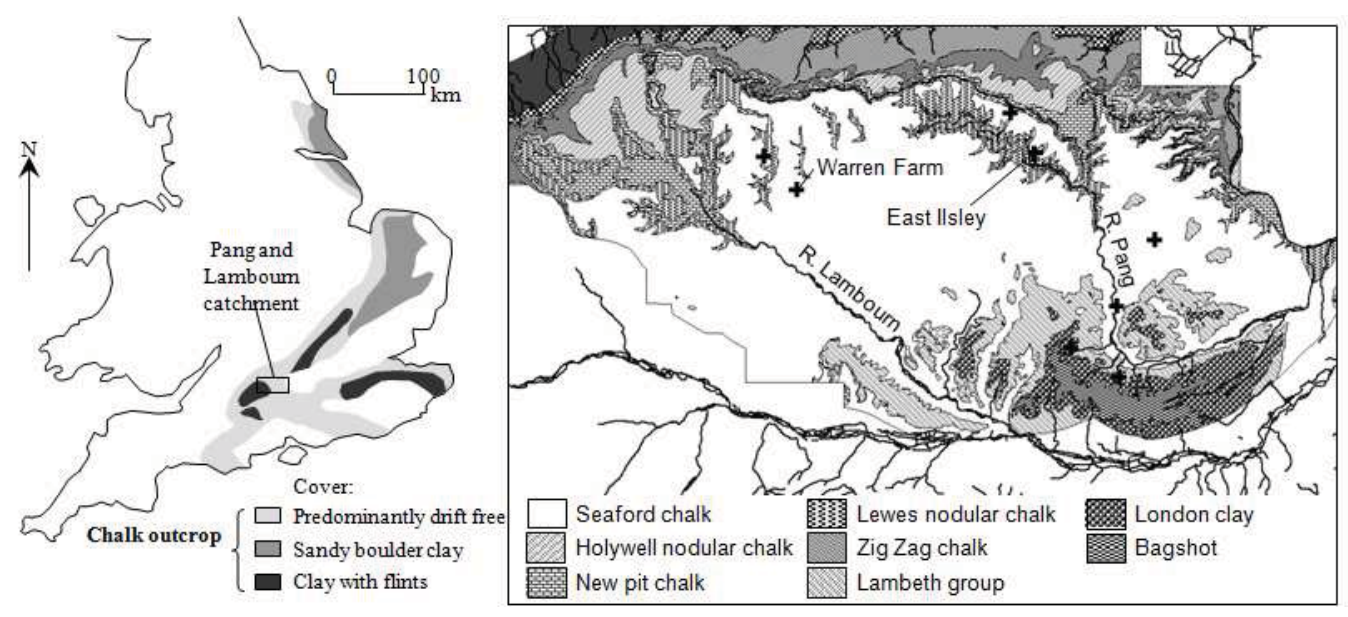

Fig. 1. Location of the catchments and field sites

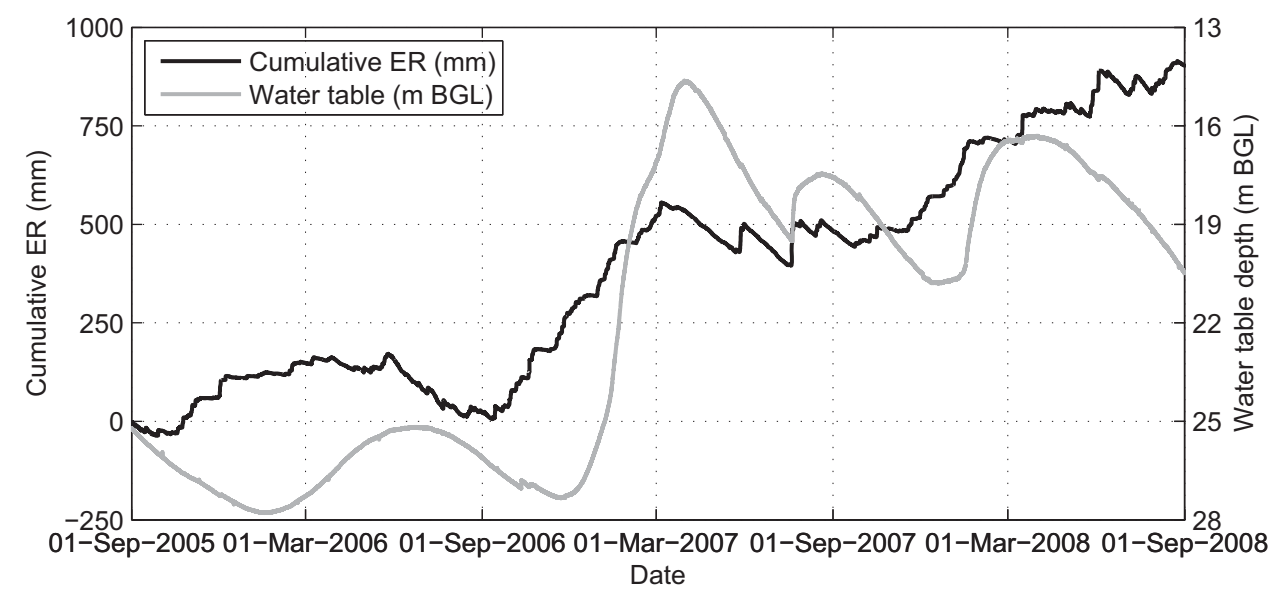

Fig. 2. Water table response to cumulative effective rainfall at East Ilsley 


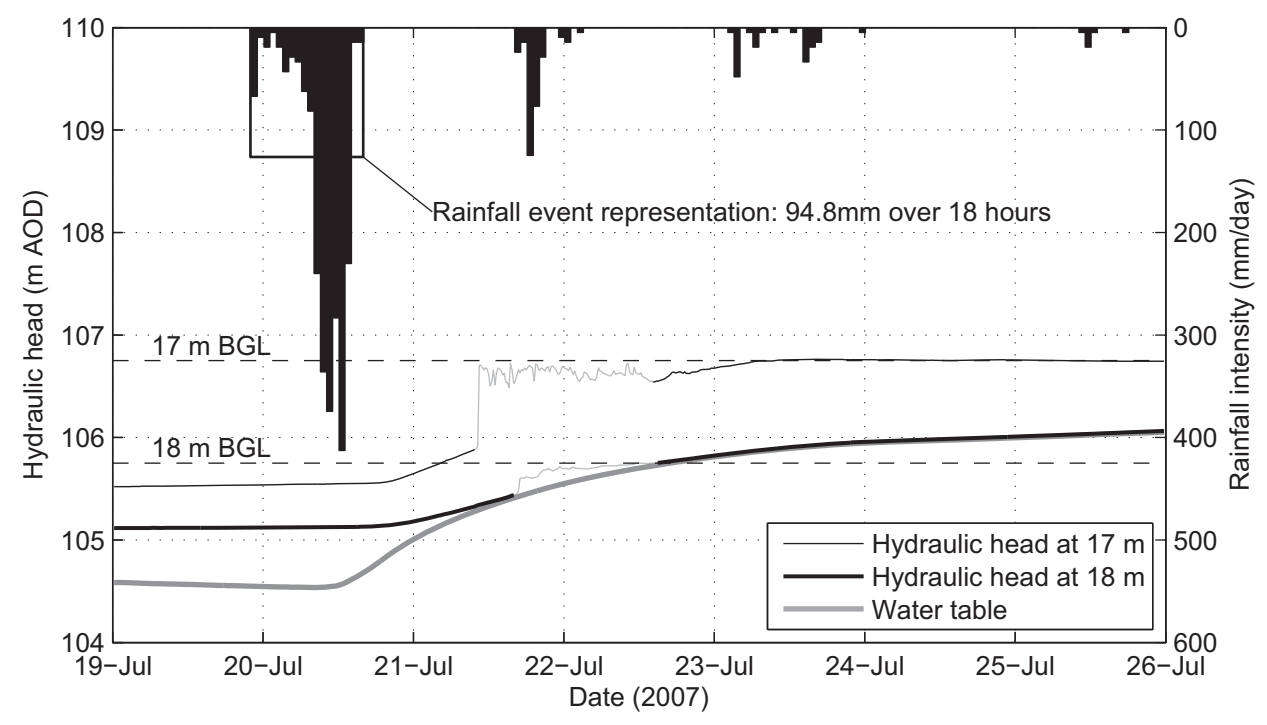

Fig. 3. Response to the rainfall event on 20th July 2007
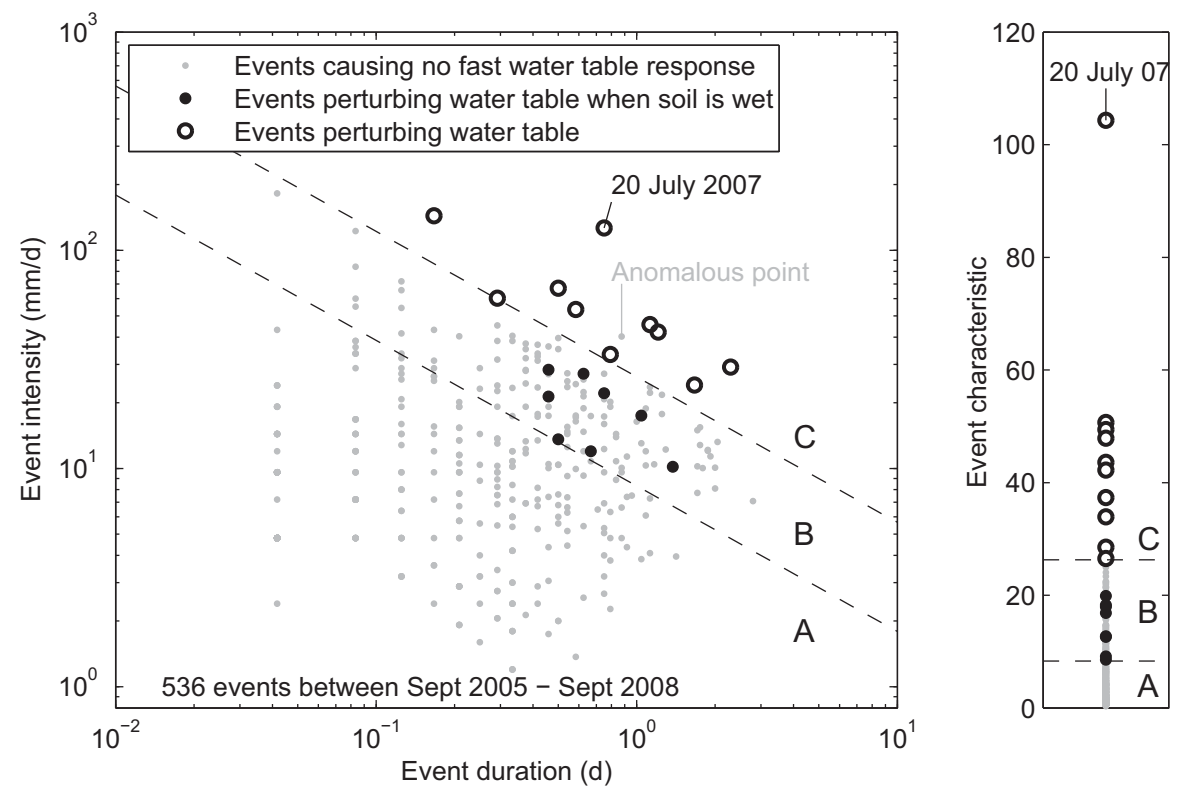

Fig. 4. Rainfall mean intensity versus duration (left) and Event Characteristic, EC, (right) 


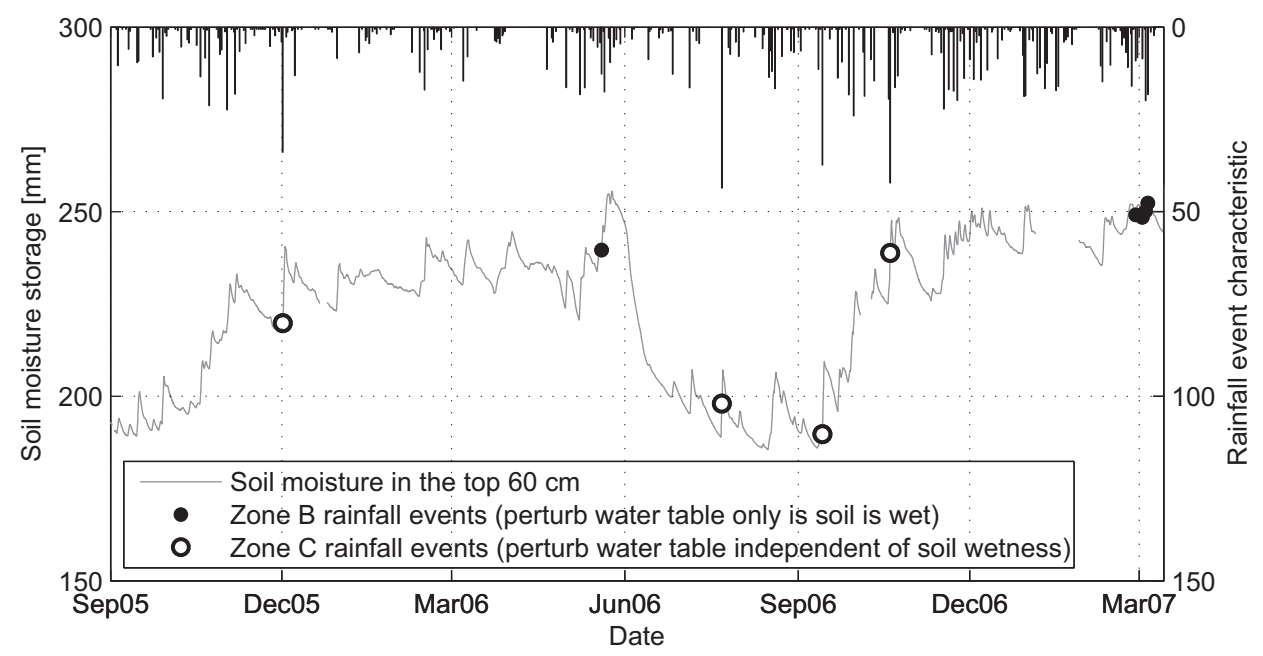

Fig. 5. Observed soil moisture storage in the top $60 \mathrm{~cm}$, showing occurrence of EC region $\mathrm{B}$ and $\mathrm{C}$ rainfall events 

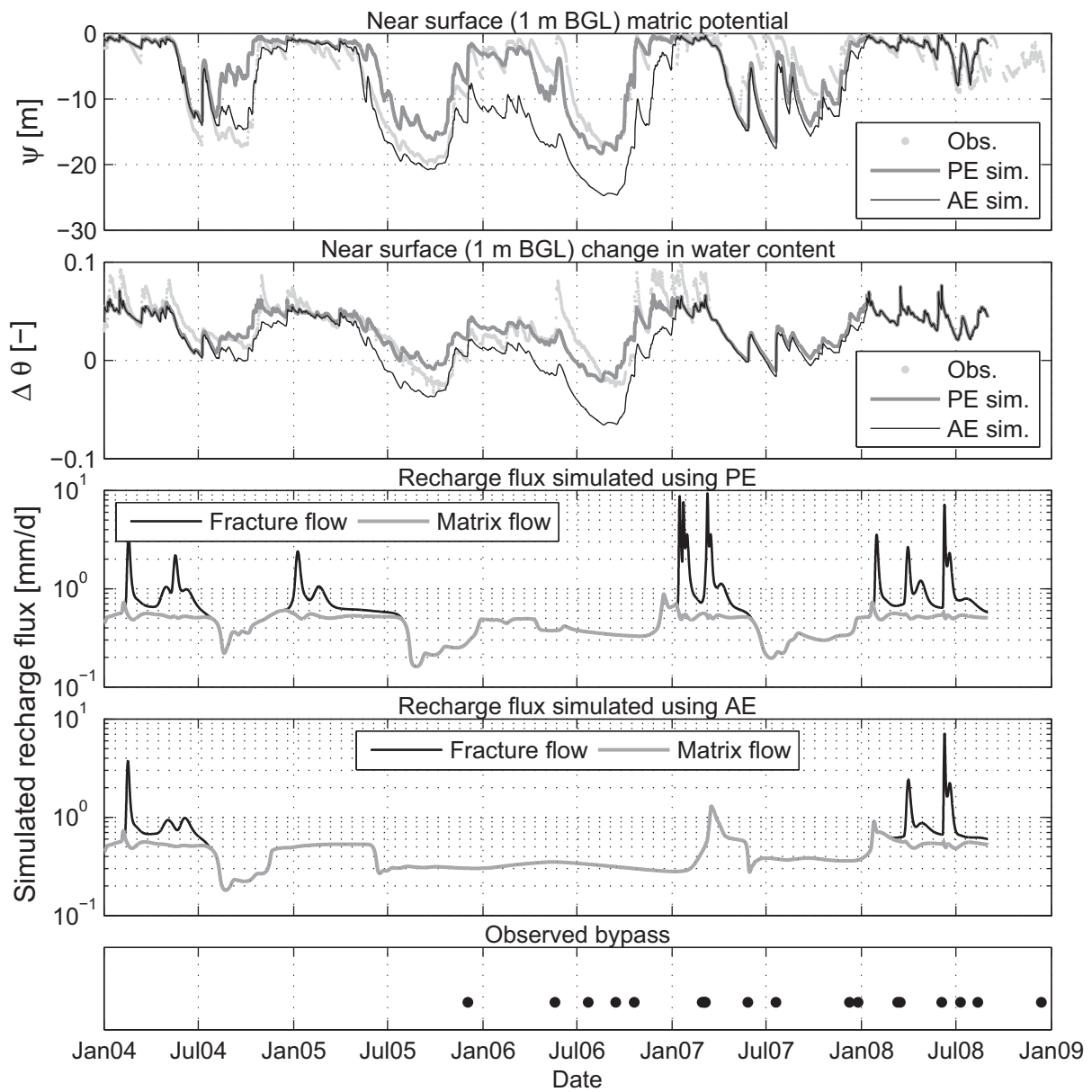

Fig. 6. Observed soil moisture data from Warren Farm compared with the model of Ireson et al. (2009b), driven using actual evapotranspiration, AE, estimated from eddy flux correlation and Penman Monteith reference crop evapotranspiration, PE 


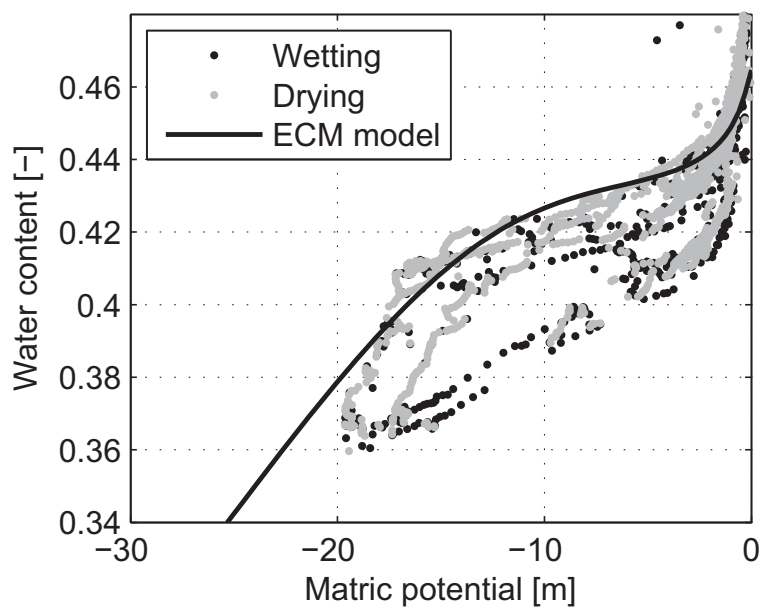

Fig. 7. Observed hysteretic soil moisture characteristic

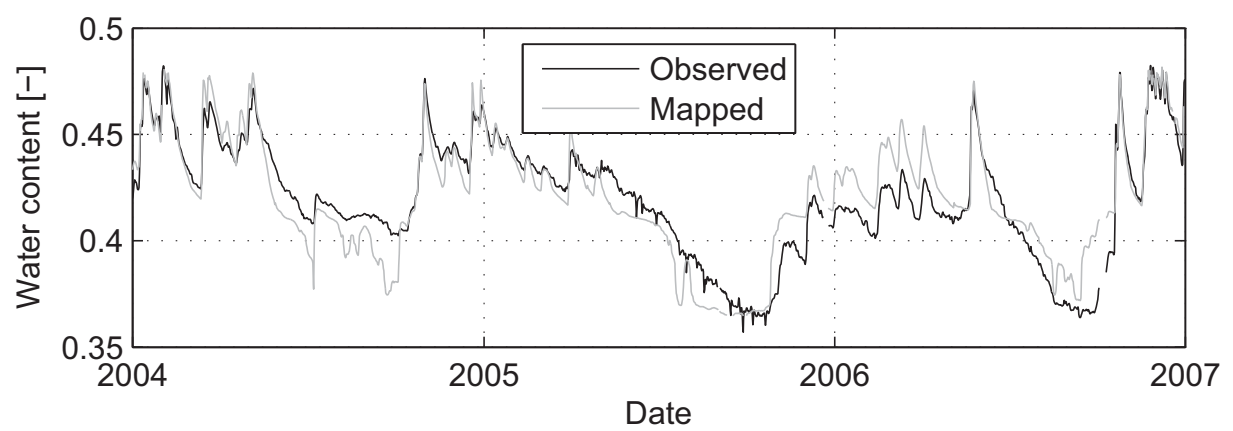

Fig. 8. Consistency of water content and matric potential observations: Observed water content vs water content obtained from matric potential using quantile mapping 


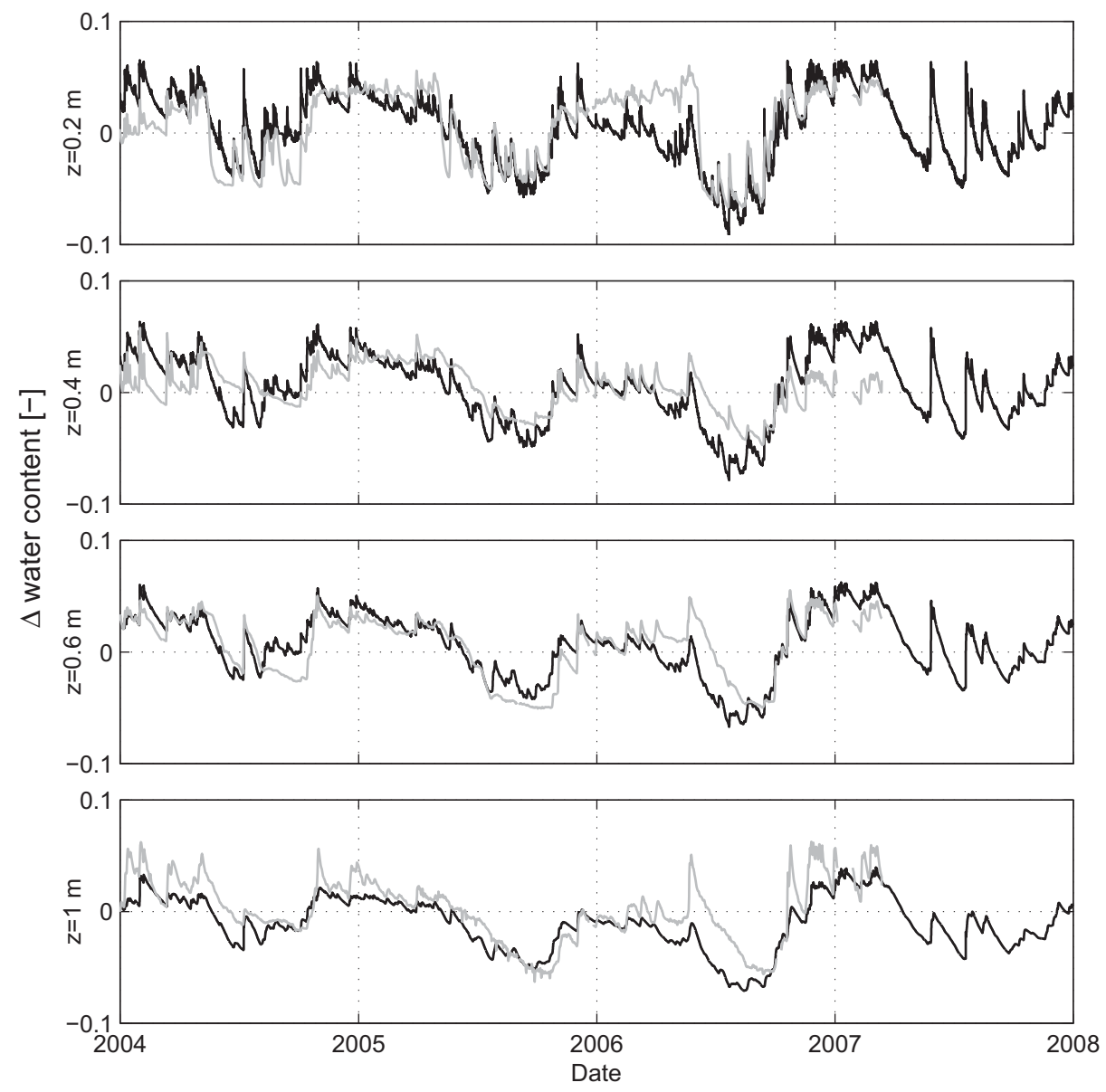

Fig. 9. Performance of the refined DCM model to reproduce observed changes soil moisture content at Warren Farm 


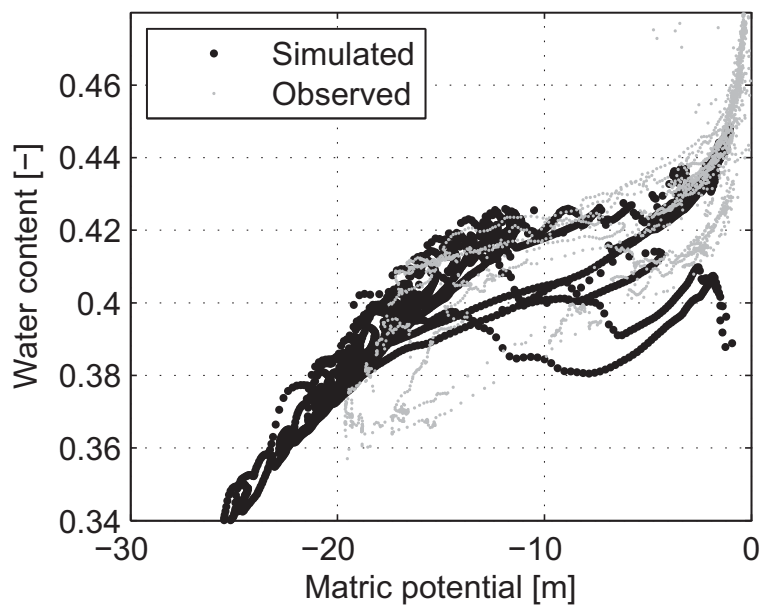

Fig. 10. Observed and simulated hysteretic soil moisture characteristic at $1.0 \mathrm{~m}$ depth

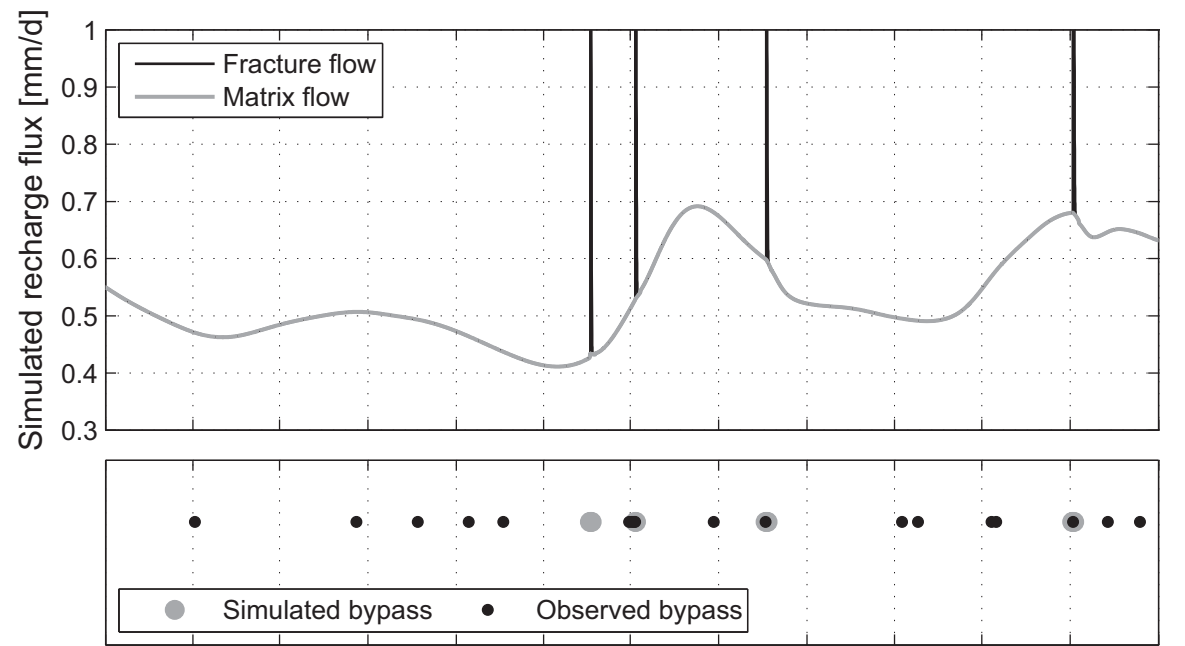

Sep05 Dec05 Mar06 Jun06 Sep06 Dec06 Mar07 Jun07 Sep07 Dec07 Mar08 Jun08 Sep08

Fig. 11. Performance of the refined DCM model to reproduce preferential recharge responses 


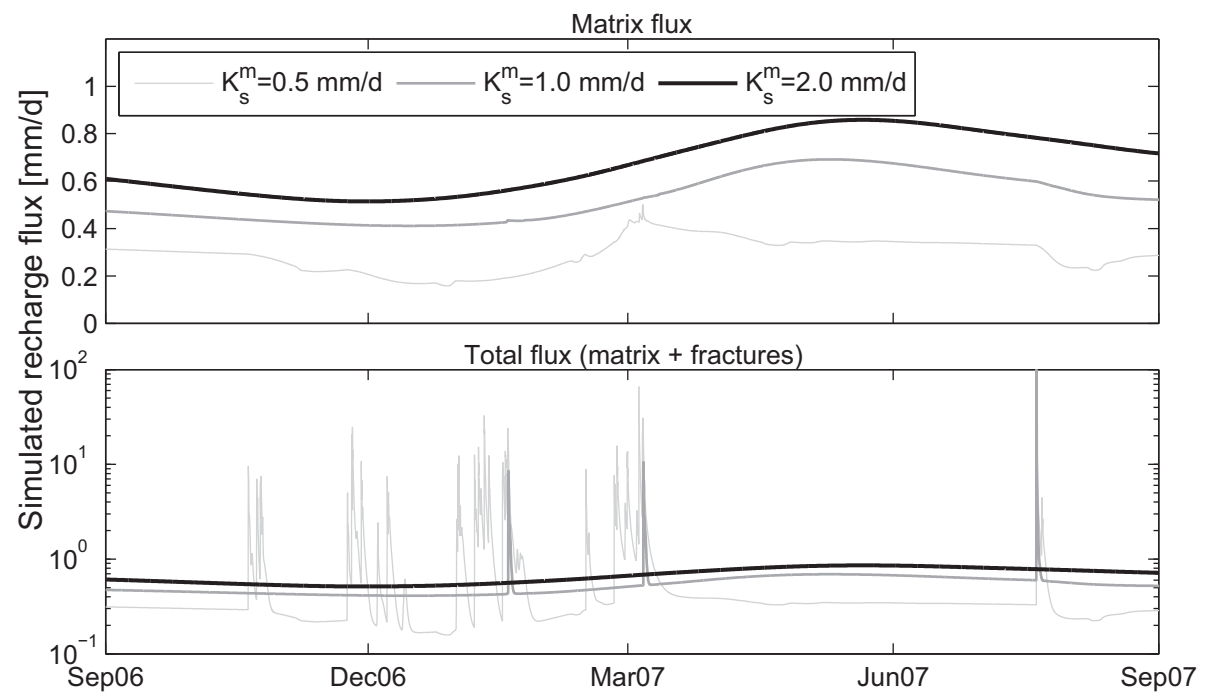

Fig. 12. Sensitivity of recharge fluxes to changes in the Chalk matrix saturated hydraulic conductivity, $K_{s}^{m}$ 

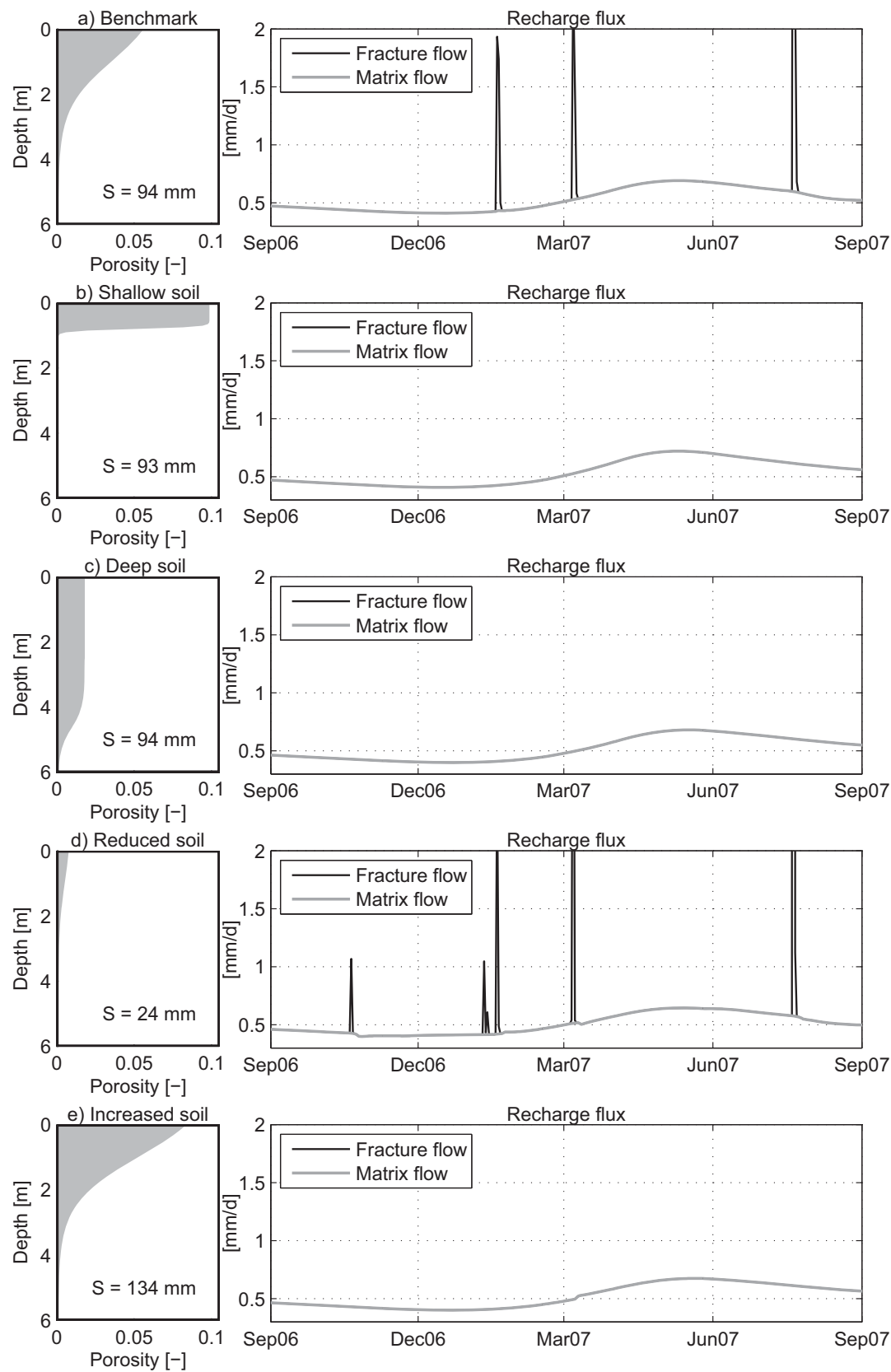

Fig. 13. Sensitivity of recharge fluxes to changes in the dynamic near surface storage in the soil/weathered Chalk 